\title{
Researchers And Teachers' Difficulties And Solution Proposals In Research Conducted At Goverment Schools
}

\author{
Ahmet Salih Şimşek \\ Cumhuriyet University, Faculty of Education, asalihsimsek@gmail.com \\ Eren Can Aybek \\ Eskişehir Osmangazi University, Faculty of Education, erencan@aybek.net
}

This paper aims to define difficulties and solution proposals of teachers and researchers for the researches conducted at government schools. Phenomenology design was used. Data were collected with interview form consist of three questions. Research group was created with purposive sampling. Research group was participated in eight researchers and eight teachers. Data were analyzed with content analysis, theme was created and frequencies are calculated. According to the results, participants reported the following research difficulties: long duration of research approval process, absence of feedback to teachers, involuntary participation to research, and the burden of research. The participants suggested to shorten the duration of approval process, giving feedback to teachers, reducing the burden of research with conducting high quality research rather than research like undergraduate theses, and designing activities that teachers and researchers come together and develop mutual positive attitudes.

Keywords: The research process, research problems, perceptions of teachers, perception of researchers

Citation: Şimşek, A. S., \& Aybek, E. C. (2016). Researchers And Teachers' Difficulties And Solution Proposals In Research Conducted At Goverment Schools. Anatolian Journal of Education, 1(1), 19-32. https://doi.org/10.29333/aje.2016.112a 


\section{Devlet Okullarinda Yürütülen Araştirmalarda Araştirmacilar Ve Öğretmenlerin Karșilaștiklari Sorunlar Ve Çözüm Önerileri}

$\mathrm{Bu}$ araştırmanın amacı, Milli Eğitim Bakanlığı (MEB)'na bağlı okullarda yürütülen araştırmalarda, araştırmacı ve öğretmenlerin karşılaştıkları sorunları ve çözüm önerilerini belirlemektir. $\mathrm{Bu}$ amaç doğrultusunda olgubilim deseni kullanılmış ve üç maddelik bir görüşme formu ile veriler toplanmıştır. Araştırmaya sekiz araştırmacı ve sekiz öğretmen olmak üzere toplam on altı birey katılmıştır. Veriler içerik analizi ile çözümlenmiş, temalar oluşturulmuş ve frekans analizi yapılmıştır. Analiz sonuçlarına göre; izin sürecinin uzun olması, geribildirim verilmemesi, veri toplama araçlarına gönülsüz katılım, öğretmenlerin araştırma yükünün fazla olması öncelikli sorunlar olarak belirtilirken; izin sürecinde bürokrasinin azaltılması, araştırma sonuçları hakkında katılımcılara geribildirim verilmesi, bitirme tezleri gibi lisans düzeyindeki araştırmalar yerine nitelikli araştırmaların okullarda yürütülmesi ve böylece öğretmenler üzerindeki araştırma yükünün azaltılması, öğretmen ve araştırmacıların bir araya gelebileceği etkinliklerin düzenlenmesi ve karşıllklı olumlu tutumların geliştirilmesi ise çözüm önerileri olarak öne çıkmaktadır.

Anahtar Kelimeler: Araştırma süreci, araştırmada karşılaşılan sorunlar, öğretmen görüşleri, araştırmacı görüşleri

\section{GİRiş}

Araştırmadan araştırmaya değişmekle birlikte, araştırmacılar araştırma sürecinin farklı aşamalarında farklı sorunlarla karşılaşabilmektedir. Bilimsel araştırma basamakları göz önüne alındığında veri toplama süreci, denencelerin kurulmasından hemen sonra yer almakta ve araştırma probleminin çözülmesinde nesnel ve sistematik bir yaklaşım sağlamaktadır. Dolayısıyla verilerin toplanması, araştırma sürecinin en önemli aşamalarından biridir. Nitekim Turgut (1983) özellikle doğa ve toplum bilimlerinin teori ve gözlem arasındaki bağıntıların derinleştirilmesiyle gelişeceğini; bunun ise ölçme işlemi ile kesin verilere dayanmasıyla mümkün olacağını ifade etmiştir.

Genel olarak eğitim bilimlerinde yapılan araştırmalarda veliler, öğrenciler, öğretmenler ve yöneticiler başta olmak üzere ilgili paydaşların araştırma sürecinde yer almasını gerektiren araştırma konuları ele alınmaktadır ve okulların eğitim bilimleri için çok önemli bir bilgi kaynağı olduğu açıktır. Bu noktada, araştırmacılar çalışmalarını Milli Eğitim Bakanlığı (MEB)'na (MEB) bağlı okullarda yürütmek durumunda kalmaktadır. Araştırmacıların, bu okullarda araştırmalarını yürütebilmeleri için Milli Eğitim Bakanlı̆̆ı'na Bağlı Okul ve Kurumlarda Yapılacak Araştırma ve Araştırma Desteğine Yönelik İzin ve Uygulama Yönergesi (Milli Eğitim Bakanlığı [MEB], 2007) 
doğrultusunda uygulama izinlerini alması gerekmektedir. Uygulama izinleri alınmasına rağmen, okullarda öğretmen ve okul müdürlerinin yaklaşımları veri toplama sürecini etkileyebilmektedir. Özellikle hem öğretmenleri hem de öğrencileri konu edinen araştırmalarda öğretmenler araştırma sürecinde oldukça önemli bir role sahiptir.

Shkedi (1998), araştırma sürecindeki önemli rolüne karşıllı öğretmenlerin akademik makaleleri okuma konusunda istekli olmadıklarını belirtmiştir. Bunun nedeni olarak ise akademik dilin anlaşılabilirliğinin öğretmenlere zor gelmesini, akademik makalelerin teoride kalmasını ve makalede yer alan sonuçların uygulanabilir olmamasını göstermişlerdir. Bununla birlikte Williams ve Coles (2007) ise, yaptıkları çalışmada 2030 yaş aralı̆̆ındaki öğretmenler ile daha önce bir araştırmada yer almış ya da halen bir araştırmada yer alan öğretmenlerin araştırmalara daha olumlu baktıklarını belirtmiş̧ir. Öğretmenlerin araştırmalara ilişkin yaklaşımları özellikle veri toplama aşamasında araştırmacıları zorlayabilmektedir. Akbulut, Şahin ve Çepni (2013) tarafindan yapılan araştırmada lisansüstü öğrencilerinin tez yazım sürecinde karşılaştıkları problemler derinlemesine incelenmiş ve araştırmaya katılan altı katılımcından beşi tezin uygulama aşamasında izin sorunu ve öğretmen problemi yaşadığını belirtmiş̧tir. Akbulut ve diğerleri (2013, s.57) tarafindan yapılan nitel çalışmada araştırmacılara ait bazı ifadeler şu şekildedir;

"Okulda onlarin dersine engel olacak bir durum olduğu zaman izin almak zor.....̇zin alsanız bile gittiğiniz okulda problem çıkartıyorlar."

“...Öğretmen problemi yaşadık çünkü çalışmamızı kabul edecek öğretmen bulmada biraz zorlandik..."

"Tezimi, öğretmen adayları ile yürüttüğüm için lisede çalışma yürütmeye göre daha az zahmet çektim diyebilirim.

Eğitim araştırmacılarının araştırma sürecinde yaşadıkları sorunlar özellikle deneysel araştırmalarda uygulamaların sağlıklı bir şekilde yapılamamasına, sürecin uzamasına veya kullanılan yöntemin mecburen değiştirilmesine neden olabilmektedir. Uygulama sürecinde yaşanan aksaklıklar sonuç olarak toplanan verilerin geçerliğini olumsuz yönde etkileyebilmektedir. Bununla birlikte araştırmacıların yaşamış oldukları sıkıntılar dikkate alınırken araştırma sürecine ilişskin öğretmen görüşleri ihmal edilebilmektedir. Oysaki öğretmenlerin uygulayıcı veya katılımcı olarak yer aldıkları araştırmalarda araştırmanın sağlıklı bir şekilde yürütülmesi için araştırmacı ve öğretmen arasındaki işbirliği oldukça önemlidir. Bu önemine karşın literatürde araştırma sürecinde yaşanan sorunlara ilişkin olarak öğretmen ve araştırmacıların görüşlerinin derinlemesine incelendiği bir araştırmanın bulunmaması bu araştırmanın problemini oluşturmaktadır. 
Türkiye'de eğitim bilimleri alanında yayınlanan yaklaşık 18 süreli yayın, üniversitelerce yayınlanan yaklaşık 40 dergi ve çevrimiçi olarak yayınlanan yaklaşı 35 dergi bulunmaktadır (WEB_1, 2012). Bu dergiler farklı alanlarda hazırlanan araştırmaları yayınlamakla birlikte özel olarak sadece ilköğretim alanında yapılan araştırmaları içeren dergilerde bulunmaktadır. Eğitim bilimleri alanında yayın yapan dergiler, ülkemizde bu alanda sarf edilen enerji ve kaynaklar düşünüldüğünde araştırma sürecinde yaşanan aksaklıkların belirlenmesi ve giderilmesi konusundaki gerekliliği gözler önüne sermektedir.

$\mathrm{Bu}$ araştırmanın amacı, MEB'e bağlı okullarda yürütülen araştırmalarda, araştırmacı ve öğretmenlerin karşılaş̧ıkları sorunları ve çözüm önerilerini belirlemektir. Bu genel amaç doğrultusunda aşağıdaki sorulara cevap aranmıştır:

1. Araştırmacıların ve öğretmenlerin, MEB'e bağlı okullarda yürütülen araştırmaların bilimsel bilgi birikimine katkı sağlaması konusundaki düşünceleri nelerdir?

2. Araştırmacı ve öğretmenlerin, MEB'e bağlı okullarda yürütülen araştırmalar sırasında varsa yaşadığı sorunlar nelerdir?

3. Araştırmacı ve öğretmenlerin, MEB'e bağlı okullarda yürütülen araştırmalar sırasında yaşadıkları sorunlara ilişkin çözüm önerileri nelerdir?

\section{YÖNTEM}

$\mathrm{Bu}$ araştırma nitel araştırma türünde bir araştırmadır. Araştırma deseni olarak olgubilim deseni kullanılmıştır.

\section{Çalışma Grubu}

Araştırma grubunun oluşturulmasında olasılığa dayalı olmayan örnekleme yönteminden amaçlı örnekleme tekniği kullanılmıştır. Amaçlı örneklemede araştırmacı ve öğretmen olacak şekilde iki grup oluşturulmuştur. Araştırmacıların araştırma grubuna seçilmesinde ölçüt olarak MEB'e bağlı okullarda en az iki araştırma yapmış olması şartı aranmıştır. Öğretmenlerin araştırma grubuna seçilmesinde ise en az bir bilimsel araştırmada katılımcı/denek vb. rollerde bulunmuş olması ölçüt olarak belirlenmiştir. Ulaşılabilirlik açsından katılımcılar, Eskişehir ve Sivas illerinde bulunan ve bu şartları sağlayan bireylerden seçilmiştir. Bu şekilde Sivas ilinden 4 araştırmacı, 4 öğretmen ile Eskişehir ilinden 4 araştırmacı, 4 öğretmen araştırma grubunu oluşturmuştur.

\section{Veri Toplama Araçları}

Araştırmada, araştırmacılar tarafından hazırlanan yarı yapılandırılmış bir görüş formu kullanılmıştır. Formun hazırlanmasında iki ölçme değerlendirme uzmanından görüş 
alınmıştır. Verilerin toplanması için kullanılan görüş formunda yönerge ile birlikte aşağıdaki sorular yer almıştır.

1. Sizce Milli Eğitim Bakanlığı'na bağlı okullarda yürütülen araştırmalar bilimsel bilgi birikimine katkı getirmekte midir? Neden?

2. Milli Eğitim Bakanlığı'na bağlı okullarda yürütülen çalışmalar sırasında -varsakarşılaştığınız sorunlar nelerdir?

3. Yaşadığınız sorunlara ilişkin çözüm önerileriniz nelerdir?

\section{İşlem}

Araştırma verilerinin toplanması için görüş formu çevrimiçi ortama (e-anket.net) aktarılmış ve bağlantı adresi araştırmaya gönüllü olarak katılmayı kabul eden sekiz araştırmacı ve sekiz öğretmenin e-posta adreslerine gönderilmiştir. Bir hafta içerisinde katılımcılardan dönüşs sağlanmıştır. Araştırmacı katılımcıların tamamı formu eksiksiz doldururken, öğretmen katılımcılardan altısı geri dönüş yapmış ve geri dönüş yapmayan iki öğretmenin yerine iki yeni öğretmene daha formlar gönderilerek geri dönüş sağlanmıştır. Bu şekilde toplanan görüş formları ile nitel veri seti oluşturulmuştur.

\section{Verilerin Analizi}

Verilerin incelenmesi aşamasına geçilmeden önce ardışık kelime grupları ve cümleler kayıt birimi olarak seçilmiştir. Daha sonra katılımcıların görüşleri iki kodlayıcı tarafından bağımsız olarak içerik analizi tekniği kullanılarak çözümlenmiştir. İçerik analizinin yapılmasında Nvivo 8 paket programı kullanılmıştır. Kodlama güvenirliği için Cohen's Kappa katsayısı incelenmiş ve $\kappa=.91$ bulunmuştur. Kodlama güvenirliğinin yüksek olması sonucunda ilgili temalar için frekanslar belirlenmiş ve çıtılar raporlanmıştır.

\section{BULGULAR}

\section{Bilimsel Bilgi Birikimine Katkı Getirmesine İlişkin Görüşler}

Araştırmacı ve öğretmenlerin, MEB'e bağlı okullarda yürütülen çalışmaların bilimsel bilgi birikimine katkı getirip getirmediğine ilişkin görüşleri temalar halinde Tablo 1'de verilmiştir.

Tablo 1

MEB’e Bağglı Okullarda Yürütülen Araştırmaların Bilimsel Katkısı Hakkındaki Görüşler 


\begin{tabular}{ccc}
\hline Araştırmanın Geçerliği & 3 & 1 \\
Saha Çalışmalarının Önemi & 3 & 1 \\
Sorunların Tespit Edilmesi & 5 & 2 \\
\hline Katkı Getirmiyor & Araştırmacı & Öğretmen \\
\hline Verilerin Geçerliğinin Düşük Olması & 1 & 5 \\
Gönülsüz Katılım & 1 & 3 \\
Ölçme İşleminin Geçerliği & 1 & 5 \\
Sonuçların Dikkate Alınmaması & 3 & 3 \\
Popüler Konuların Seçilmesi & 0 & 1 \\
\hline N $_{\text {Araștırmacı }}=8 ;$ Nöğretmen $=8$ & &
\end{tabular}

Temalar incelendiğinde katılımcılar, araştırmaların, araştırma geçerliğinin sağlandığı durumlarda bilimsel bilgi birikimine katkı getirildiğini; okulların eğitim araştırmaları için birer saha görevi gördüğünü ve bu araştırmaların eğitim sistemindeki sorunların tespitinde önemli rol oynadığını ifade etmişlerdir. Katılımcıların ilgili temalara dağımı incelendiğinde; araştırmacıların büyük bir kısmının öğretmenlerin ise çok az bir kısmının MEB'e bağlı okullarda yürütülen araştırmaların bilimsel bilgi birikimine katkı getirdiğini düşündükleri görülmektedir.

Araştırmacı ve öğretmenlere ait örnek görüşler şu şekildedir:

A3 (Araştırmac1-3): “Araştırmanın bilimsel ilkelere uygunluğu ile doğru orantılldır. Bilimsel, geçerliği ve güvenirliği kanıtlanmış bir araștırma elbette alana katkı sağlayacaktır."(Araştırmanın geçerliği)

A1: "MEB'e bağll okullarda ne kadarının uygulamaya koyulduğu konusunda slkintılar mevcut." (Sonuçların dikkate alınmaması)

Ö1 (Öğretmen - 1): "Elbette, Milli Eğitim Bakanlığı bu işin mutfă̆ı̆dır." (Saha çalışmalarının önemi)

Ö8: "Araştırmanın sonuçlarından haberdar edilmiyoruz, yani bilimsel bir katkı getiriyorsa da bunu formu yanttlayanlar bilmediği için bir sonraki çalı̧̧maya da isteksiz biçimde katıllyor/katılmıyorlar." (Sonuçların dikkate alınmaması) 
MEB'e bağlı okullarda yürütülen araştırmaların bilimsel bilgi birikimine katkı getirmediğini düşünen katılımcıların görüşleri ise katılımın gönülsüz olduğunu, ölçme işleminin geçerliğinin olmadığını ve dolayısıyla araştırmalarda toplanan verilerin geçerliğinin düşük olduğunu; araştırma sonuçlarının dikkate alınmadığını ve popüler konuların araştırma konusu yapıldığı yönündedir. Katkı getirilmediğini düşünen araştırmacı ve öğretmenlere ait örnek görüşler şu şekildedir:

A1: MEB'e bağlı okullarda ne kadarının uygulamaya koyulduğu konusunda sıkıntılar mevcut. (Sonuçların dikkate alınmaması)

A4: Bu konuda çok fazla ölçme aracıyla karşılaştıklarından artık ciddiyetsiz bulmaları (Gönülsüz katılım)

Ö8: Araştırmanın sonuçlarından haberdar edilmiyoruz, yani bilimsel bir katkı getiriyorsa da bunu formu yanıtlayanlar bilmediği için bir sonraki çalışmaya da isteksiz biçimde katılıyor/katılmıyorlar. (Sonuçların dikkate alınmaması)

Ö5: Öğretmenlerin, tamamına yakınının, anket formlarını ciddiyet ve dürüstlükle doldurduğunu düşünmüyorum. (Verilerin geçerliğinin düşük olması)

\section{Okullarda Karşılaşılan Sorunlara İliş̧kin Görüşler}

Araştırmacı ve öğretmenlerin MEB’e bağlı okullarda yürütülen araştırmalarda varsa yaşadıkları sorunlara ilişkin görüşleri temalar halinde Tablo 2'de sunulmuştur.

Tablo 2

MEB’e Bağlı Okullarda Yürütülen Araştırmalarda Karşılaşılan Sorunlar Hakkındaki Görüşler 


\begin{tabular}{lcc}
\hline Karşılaşılan Sorunlar & Araştırmacı & Öğretmen \\
\hline Olumsuz Tutumlar/Önyargılar & 6 & 3 \\
İzin Süreci & 7 & 3 \\
İzin Sürecinin Uzun Olması & 7 & 0 \\
Araştırmaların İzinsiz Yapılması & 0 & 3 \\
Geçersiz Veri Toplama Süreci & 4 & 4 \\
Gelişi-güzel Yanıtlama & 3 & 3 \\
Katılım Olmaması & 4 & 0 \\
Nitelikleri Düşük Ölçme Araçları & 2 & 2 \\
Yönerge Eksikliği & 1 & 1 \\
Plansız Çalışma & 1 & 1 \\
Araştırma Yükü & 3 & 4 \\
Araştırma Sayısının Fazla Olması & 1 & 1 \\
Araştırmaların Zaman Alıcı Olması & 2 & 4 \\
Araştırmaya Müdahaleci Yaklaşımlar & 4 & 1 \\
\hline N & & \\
\hline
\end{tabular}

$$
\mathrm{N}_{\text {Araştrmacı }}=8 ; \mathrm{N}_{\text {Öğretmen }}=8
$$

Araştırmacılar yaşadıkları sorunların başında izin süreci (f $=7$ ) ve olumsuz tutum/önyargıların ( $\mathrm{f}=6$ ) geldiğini belirtmişlerdir. İzin süreci ve olumsuz tutum/önyargılar temalarında az sayıdaki öğretmende görüş bildirmektedir. Ancak içerikleri incelendiğinde olumsuz tutum/önyargılar teması altında görüş bildiren araştırmacıların öğretmenlik ve bakanlık çalışanlarından araştırmacılara yönelik olumsuz tutum ve önyargıların olduğunu belirttikleri görüşmüştür. Aynı tema altında görüş bildiren öğretmenler ise olumsuz tutum/önyargıların öğretmenlerden araştırmacılara yönelik olduğunu doğrulamakla birlikte bunların yapılan araştırmalarla ilişkili olduğunu ifade etmişlerdir. Olumsuz tutum/önyargılarda teması altındaki örnek araştırmacı ve öğretmen görüşleri şu şekildedir;

Ö1: Bu veri toplama araçlarından bazıları sınav niteliğinde oluyor $k i$ bu da ögretmenler içinde hoş karşılanmayan bir durum (Olumsuz tutum/Önyargılar)

Ö6: Öğretmenlerin yöneticilerin bu işleri formalite olarak görmeleri, bu işlerin gereksizliğine inanmaları (Olumsuz tutum/Önyargılar) 
A1: Bunun yaninda en önemli sorun, bence ögretmenlerin araştırmactlara fazlaca önyargılı olmaları (Olumsuz tutum/Önyargılar)

A4: Milli Eğitim Bakanlığına bağlı okullarda yürütülen araştırmalar sırasında en fazla karşılaşılan sorunların başında bakanlık ya da okul yetkililerinin araştırmalara karşı olumsuz tutumlarıdır (Olumsuz tutum/Önyargilar)

Bununla birlikte izin süreci teması altında yer alan görüşler incelendiğinde araştırmacı ve öğretmenlerin farklı düşündükleri görülmektedir. Araştırmacıların büyük bir kısmı izin sürecinin uzun olduğunu, öğretmenler ise izinsiz uygulama yapıldığını belirtmiştir. $\mathrm{Bu}$ temaya ilişkin örnek araştırmacı ve öğretmen görüşleri şu şekildedir;

A2: En ufak bir iş için bile izin soruyorlar, tanıdık yoksa iş yaş. izin süreci ise tam bir işkence (İzin Sürecinin Uzun Olması)

Ö7: İzinsiz gelen çalı̧̧malar oluyor (Araştırmaların İzinsiz Yapılması)

Çizelge 2 incelendiğinde öğretmenlerin çoğunlukla araştırma yükü $(f=4)$ ve veri toplama sürecinin geçerliği $(f=4)$ teması altında görüş bildirdiği görülmektedir. Nitekim Büyüköztürk (2005) ankette yer alan madde sayısının artmasına bağlı olarak cevaplama süresinin arttı̆̆ını, cevaplamaya ilişkin güdünün azaldığını, yorgunluğa bağlı olarak düşünmeden cevap verme olasılığının arttı̆̆ını belirtmiştir. İlgili temalar altında örnek araştırmacı ve öğretmen görüşleri şu şekildedir;

Ö1: Öncelikle üniversiteye çok yakın bir okul olduğumuz için çok fazla veri toplama aracı geliyor (Araştırma Sayısının Fazla Olması)

Ö6: Öğretmenlerin yöneticilerin bu işleri formalite olarak görmeleri ve anket doldurmaktan sıkıldıkları için okumadan yanıtlamaları (Gelişi-güzel Yanıtlama)

Ö8: Gelen formlarda maddeler arasında çoğu zaman tutarsızlıklarla karşılaşıyoruz, ya da maddelerin konu alanı çok dă̆gnık oluyor, neyi nasıl ölçmeye çalıştı̆̆g konusu net anlaşılmıyor (Nitelikleri Düşük Ölçme Araçları)

\section{Karşılaşılan Sorunlara İlişsin Çözüm Önerilerine İlişskin Görüş̧ler}

Araştırmac1 ve öğretmenlerin, MEB'e bağlı okullarda yürütülen araştırmalarda karşılaştıkları sorunlara ilişkin çözümlerine dair görüşleri temalar halinde Tablo 3 'te verilmiştir.

Tablo 3

MEB'e Bağlı Okullarda Yürütülen Araştırmalarda Karşılaşılan Sorunlara Yönelik Çözüm Önerileri Hakkındaki Görüşler 


\begin{tabular}{ccc}
\hline Çözüm Önerileri & Araşırıacı & Öğretmen \\
\hline İzin Süresinin Kısaltılması & 8 & 3 \\
Bürokrasinin Azaltılması & 6 & 1 \\
İzin Alınmasının Kaldırılması & 1 & 0 \\
MEB'nın Nitelikli Personel Bulundurması & 2 & 2 \\
Karşılıklı Olumlu Tutumların Geliştirilmesi & 3 & 2 \\
Geri Bildirim Verilmesi & 2 & 2 \\
Araştırma Yükünün Azaltılması & 2 & 2 \\
Nitelikli Araştırmalara İzin Verilmesi & 2 & 0 \\
İzinsiz Araştırma Yapılmaması & 1 & 2 \\
Araştırmaların Teşvik Edilmesi & 1 & \\
\hline
\end{tabular}

$$
\mathrm{N}_{\text {Araştrrmacı }}=8 ; \mathrm{N}_{\text {Öğretmen }}=8
$$

Katılımcılar çoğunlukla izin süresinin kısaltılması yönünde görüş bildirirken $\left(f_{A+O}=11\right)$, karşılıklı olumlu tutum ve davranışların geliştirilmesi $\left(f_{A+O}=5\right)$, geri bildirim verilmesi $\left(f_{A+O ̈}=4\right)$ ve araştırma yükünün azaltılması $\left(f_{A+O ̈}=4\right)$ da çözüm önerileri arasında yer almıştır. Çizelge 3 incelendiğinde araştırmacıların çözüm önerisi olarak bürokrasinin azaltılması $(f=6)$ yoluyla izin süresinin kısaltılması ve karşılıklı olumlu tutum geliştirilmesini ( $f=3$ ) önemsediği görülmektedir. Ayrıca araştırmacılar araştırmalar sonucunda geri bildirim verilmesi gerektiği $(f=2)$ ve nitelikli araştırmalara izin verilerek $(f=2)$ okullardaki araştırma yükünün kaldırılması gerektiğini ifade etmişlerdir. $\mathrm{Bu}$ temalarda öğretmenler ile benzer ölçüde savunulan temaların geribildirim verilmesi ve araştırmaların teşvik edilmesi olduğu söylenebilir. İlgili temalardaki örnek araştırmacı görüşleri şu şekildedir;

A1: Her iki kurum çalışanlarının birbirine karşı olan önyargılarını ylkabilmek için ortak projeler, buluşma günleri vs. yapılabilir (Karşılıklı Olumlu Tutum Geliştirilmesi)

A4: Bu konuda yapılan araştırma sonuçlarının yetkililerle paylaşılması araşttrmaya yönelik duyarlılığı geliștirebilir (Geribildirim Verilmesi)

Öğretmenlerin çözüm önerileri incelendiğinde ise en önemli çözüm önerileri olarak izin süresi temasının altında bürokrasinin azaltılması $(f=1)$ ve MEB'nın nitelikli personel bulundurulması $(\mathrm{f}=2)$, geribildirim verilmesi $(\mathrm{f}=2)$, araştırma yükünün azaltılması $(\mathrm{f}=$ 
2) ve karşılıklı olumlu tutumun geliştirilmesi $(f=2)$ belirtilmiştir. Bu temalara ilişkin örnek öğretmen görüşleri şu şekildedir;

Ö8: Araştırma sonuçları mutlaka bizimle paylaşılmalı ya da en azından tamamlandı̆̆ında sonuçlarına nasıl ulaşabileceğimiz konusunda bir bilgilendirme yapllmalı (Geribildirim Verilmesi)

Ö7: Araştırmalar daha uygun şekilde yürütülmeli özellikle bitirme tezleri gibi çalışmalarda gerçek araştırmalar yapılmalı çok araştırma yapalım derken geçersiz formalitelere dönüşürülmemeli (Araştırma Yükünün Azaltılması)

\section{TARTIŞMA}

Katılımcıların görüşleri incelendiğinde; araştırmacıların çoğunluğu, MEB'e bağlı okullarda yürütülen araştırmaların bilimsel bilgi birikimine katkı getirdiği görüşündeyken, öğretmenlerin çoğunluğu bu araştırmaların bilimsel bilgi birikimine katk1 getirmediği görüşündedir. Araştırmacılar çoğunlukla izin süreci, araştırma sırasındaki olumsuz tutum ve davranışlar, araştırmaya katılımın sağlanamaması ve yürütülen araştırmaya müdahaleci yaklaşım sorunlarını yaşarken; öğretmenler çoğunlukla, araştırmaların zaman alıcı olması, araştırma yükünün fazla olması, veri toplama sürecinin geçersiz olması sorunlarını yaşamaktadır.

Araştırmacılar karşılaştıkları başlıca sorunun izin süresinin uzun olması ile bakanlık çalışanları, yöneticiler ve öğretmenlerin araştırmalara karşı olumsuz tutuma sahip olmaları olduğunu belirtmiştir. Ayrıca gerekli izinlerin alınmasına rağmen araştırmaya yönelik engelleyici yaklaşımların ve gelişi-güzel yanıtlamalar, araştırmaya katılım gösterilmemesinden dolayı oluşan geçersiz veri toplama sürecinin de karşıllaşılan önemli sorunlardan biri olduğunu ifade etmişlerdir. Öğretmenler sorun olarak belirttikleri durumlar ise araştırmacılardan farklı olarak izinsiz araştırma yapılması, araştırmacıların olumsuz tutum ve davranışları, çok sayıda araştırma ve veri toplama aracının kullanılmasının yük getirmesi bunlara bağlı olarak da geçersiz veri toplama sürecidir.

Araştırmaların, alanına bilimsel olarak katkı getirebilmesi için araştırmalarda kullanılan ölçme araçlarından elde edilen bilgilerin geçerli olması gerektiği açıktır. Katılımcıların da belirttiği nedenler de dahil olmak üzere, toplanan verilerin geçerliği çeşitli nedenlerle tehlike altına girmektedir. Özellikle niteliksiz ölçme araçlarının çok sık uygulandığı okullarda çalışan öğretmenler, veri toplama sürecine gönülsüz olarak katılabilmektedir. İzin sürecinin uzun oluşu ve okullarda karşılaşılan olumsuz tutumlar da, araştırmacının motivasyonunu düşürebilmektedir. İzin süreleri kısaltılarak, karşıllıklı olumlu tutum ve davranış gelişiminin sağlanması ve öğretmenler üzerindeki araştırma yükünün azaltılmasıyla araştırmaların verimliliği artabilir. 
Araştırma sonuçlarına dayanılarak ilgili kurumlara ve araştırmacılara ilişkin geliştirilen öneriler şu şekildedir;

1. MEB'e bağlı okullarda yürütülecek olan çalışmalar için izin alma sürecindeki bürokratik işlemlerin azaltılması ile izin sürecinde yaşanan aksaklıkların giderilmesi.

2. Öğretmenlere araştırma eğitimleri verilerek, araştırmacı öğretmenlerin yetişmesinin yanı sıra, araştırmacılar ile öğretmenleri bir araya getirebilecek seminerler, panel v.b. bilimsel toplantılar düzenlenerek karşılıklı olumlu tutum geliştirilmesi.

3. Araştırma sürecinin iyi planlanması ve veri toplama sürecinde okulların programlarının da dikkate alınarak en uygun zamanın öğretmenler ile birlikte belirlenmesi.

4. Araștırmalarda kullanılacak veri toplama araçlarına ilişkin en az bir alan uzmanı ile birlikte bir ölçme değerlendirme uzmanından görüş alınması ve görüşler doğrultusunda ölçme araçlarının niteliğinin geliştirilmesi.

5. Araştırma sonuçlandıktan sonra katılımcılara ve mümkünse ilgili okullara geribildirim verilmesi ile öğretmenlerin araştırmalara ilişkin duyarlılıklarının ve güdülenmelerinin artırılması.

\section{KAYNAKÇA}

Akbulut, H. İ., Şahin, Ç. ve Çepni, S. (2013). Doktora tez sürecinde karşılaşılan problemlerin belirlenmesi: Eğitim Fakültesi örneği, Dicle Üniversitesi Ziya Gökalp Eğitim Fakültesi Dergisi, 20, 50-69.

Büyüköztürk, Ş. (2005). Anket Geliştirme. Türk Eğitim Bilimleri Dergisi,3, 2.

Williams, D. \& Coles, L. (2007). Teachers' approaches to finding and using research evidence: An information literacy perspective. Educational Research, 49(2), 185-206.

Milli Eğitim Bakanlığı (MEB). (2007). Milli Eğitim Bakanlı̆ğna Bă̆ll Okul ve Kurumlarda Yapılacak Araştırma ve Araştırma Desteğine Yönelik İzin ve Uygulama Yönergesi. http://mevzuat.meb.gov.tr/html/2594_1.html adresinden 20 Mayls 2012 tarihinde alınmıştır. 
Shkedi, A. (1998): Teachers' attitudes towards research: A challenge for qualitative researchers. International Journal of Qualitative Studies in Education, 11(4), 559-577.

Turgut, F. (1983). Eğitimde ölçme ve değerlendirme metotları (ikinci baskı). Ankara: Saydam Matbaacilik.

WEB_1 (2012). http://yunus.hacettepe.edu.tr/ sadi/egitim/dergi.html adresinden 06 Nisan 2012 tarihinde alınmıştır.

\section{SUMMARY}

\section{INTRODUCTION}

Generally, in the researches carried out in the field of education, the research topics which involve the participation of mainly parents, students, teachers and administrator along with other stakeholders in the research process are taken as the basis of the research and it is clear that the schools are an important source of information for the field of education. At this point, the researchers have to carry out their studies at schools that are connected to the National Education Ministry (MEB). In for them to carry out their studies, the researchers have to have a permission granted them by order. Although the permission is taken, the approaches of the teachers and the administrator at the school may make the data gathering process more difficult. Especially teachers have an important role in gathering data both from themselves and from the students.

The purpose of this study is to designate the problems that the researcher and the teachers face during the research process and to propose solutions for these problems.

\section{METHODOLOGY}

For the purpose of this study qualitative method has been taken. The research group of the study consists of 4 researchers and 4 teachers from Sivas, Turkey and 4 researchers and 4 teachers from Eskisehir, Turkey. An interview form developed specifically for the purposes of this study by the researchers has been used in the study. In the preparation of the form, two experts in measurement and evaluation field have been consulted. For the reliability of the encoder, Cohen's Kappa coefficient has been used and it has been found out that $\kappa=.91$. Since the reliability of the encoder turned out to be high, for the related themes, frequencies has been designated and results have been made into a report. 


\section{FINDINGS AND DISCUSSION}

The participants have stated that the researches contribute to the accumulation of scientific knowledge when the validity of the research has been established; that the school have functioned in a field duty for educational research purposes and that these researches play an important role in designating the problems in the education system. When the distribution the participants according to the themes, it is seen that majority of the researchers think that a small number of teachers can contribute to the accumulation of scientific knowledge regarding the researches carried out in the school connected to MEB. The views of the participants who think that there is no contribution at all related to the accumulation of scientific knowledge at schools connected to MEB include that the participation was not voluntary, that the measuring and evaluating process was not valid and therefore, the reliability of the data gathered in the researches is low; and that the results of the study have not been taken into consideration and only the popular topics have been made into the research topics.

The researchers stated that their main problems are caused when they tried to get the work permit and by negative attitudes/prejudices. A number of teachers comment on the themes of work-permit process and negative attitudes/prejudices. The teachers who commented on the same theme verified that the negative attitudes/prejudices are directed at the researchers and stated that these were connected with the research carried out.

While most of the researchers stated that the permission period should be reduced, other solutions included the development of mutual positive attitude and behaviors, giving feedback and giving less research burden on the researchers. When Figure 3 is analyzed, it is seen that the permission period should be shortened through shortening the bureaucracy and that the researchers care about developing a positive attitude. Moreover, at the end of the research, the researchers stated that feedback should be given at all times and the research burden in the schools should be lifted by giving permission for more qualified researches. It can be suggested that the teachers and the similar themes should be given feedback and the researches should be encouraged.

When the views of the participants are analyzed, while majority of the researchers think that the researches carried out at the schools connected to MEB contribute to accumulation of scientific knowledge, majority of the teachers think that they do not contribute at all. While the researchers experience problems mainly about work-permit, negative attitudes and behaviors in the research process, the lack of participants in the research and intrusive approaches during the application process, teachers experience problems about researches taking much time, the bur den being too heavy and that the data gathering is invalid. 